\title{
Cerebral venous thrombosis associated with coronavirus infection: an underestimated entity?
}

\author{
Andrea Rigamonti $^{1}$ (D) Vittorio Mantero ${ }^{1} \cdot$ Francesca Piamarta $^{1} \cdot$ Giannantonio Spena $^{2} \cdot$ Andrea Salmaggi $^{1}$
}

Received: 20 April 2020 / Accepted: 21 June 2020 / Published online: 29 June 2020

(C) Fondazione Società Italiana di Neurologia 2020

\section{Dear Editor,}

Novel coronavirus (also called SARS-CoV-2 or COVID19) was recently discovered in Wuhan, China. This virus has a prevailing tropism for the respiratory system; however, a number of studies have shown that coagulation dysfunction exists in patients with severe novel coronavirus pneumonia. In particular a pro-thrombotic state, with an increased incidence of venous thromboembolic events, has been reported [1-4]. A recent paper by Mao et al. [5] described the spectrum of neurological manifestations associated with SARS-CoV-2; among central nervous system manifestations, large vessel ischemic stroke has been reported in 6 of 214 cases $(2.8 \%)$.

To date no cases of cerebral venous thrombosis associated with COVID-19 have been reported in the literature.

A 54-year-old male with a previous negative medical history presented to the hospital with 2 weeks of cough, fatigue and fever. On the day of admission he also complained of headache and aphasia. Vital signs on presentation were $\mathrm{T}$ $38.8^{\circ} \mathrm{C}$, heart rate $88 \mathrm{bpm}$, blood pressure $140 / 80 \mathrm{mmHg}$, respiratory frequency 22 and $\mathrm{SpO} 290 \%$ on room air. Neurological examination showed non-fluent aphasia, right emianopsia and right facio-brachio-crural hemiparesis. Ddimer was $3000 \mathrm{ng} / \mathrm{mL}(\mathrm{nv}<500)$, reactive C-protein $9.7 \mathrm{mg} / \mathrm{dL}(\mathrm{nv}<1)$ and fibrinogen $936 \mathrm{mg} / \mathrm{dL}$ (nv 150 $400 \mathrm{mg} / \mathrm{dL}$ ). Nasopharyngeal swab was positive for SARSCoV-2 on real-time reverse transcriptase-polymerase chain reaction assay. Chest computed tomography $(\mathrm{CT})$ revealed

Andrea Rigamonti

rig74@libero.it

1 Neurological Department, “Alessandro Manzoni” General Hospital, Via Dell'Eremo 9/11, 23900 Lecco, Italy

2 Neurosurgery, A.O Manzoni, Via Dell'Eremo 9/11, 23900 Lecco, Italy bilateral ground glass opacities with peripheral and basilar predominance. Brain CT showed ischaemic hypodensity involving left basal ganglia and thalamo-capsular region with a small haemorrhagic hyperdensity in the context of nucleus caudatus, associated with mass effect and shift of midline structure. An angio-CT disclosed thrombosis involving deep veins of the left hemisphere. Oxygen supplementation $(15 \mathrm{~L} /$ min on a non-rebreather mask), hydroxychloroquine, azithromycin and lopinavir/ritonavir were started. Moreover anticoagulation (enoxaparin $100 \mathrm{UI} / \mathrm{kg}$ twice a day) and antiedema therapy was introduced.

Four days after hospitalisation, the neurological picture deteriorated and the patient became comatose (GCS 7). A brain CT showed an increase of cerebral edema and shift of midline structures. The patient was intubated and underwent surgical decompression. Despite this treatment the neurological picture did not improve and the patient died 10 days later.

Our patient did not present antecedent risk factors for cerebral vein thrombosis (i.e. malignancies, connective tissue disease, inflammatory bowel disease...) so we hypothesise that a pro-thrombotic state induced by COVID-19 infection was responsible for the development of such a condition.

A hallmark of severe COVID-19 is coagulopathy, with $71.4 \%$ of patients who died of COVID-19 meeting criteria for disseminated intravascular coagulation (DIC) [2]. Additionally, it has become clear that this is not a bleeding diathesis but rather a predominantly pro-thrombotic state with high risk of venous thromboembolism. More specifically, Ddimer, fibrinogen and fibrinogen degradation product are significantly increased, whereas AT III levels are lower in COVID-19 patients compared with a healthy control population [3]. The incidence of venous thromboembolism among COVID-19 patients in Intensive Care Unit seems to be somewhat higher in comparison with that reported in other studies including such patients with other disease conditions [4].

Over time, increasing evidence of neurologic manifestations of SARS-CoV-2-associated disease emerged. Mao et al. [5] reported that $36.4 \%$ of their 214 patients had nervous system 
related finding. These manifestations ranged from fairly specific symptoms (i.e. anosmia, ageusia, myopathy and stroke), to less specific symptoms (headache, seizure, dizziness). In this series 6 patients $(2.8 \%)$ presented acute cerebrovascular disease (5 large vessel ischemic stroke and 1 hemorrhage) but no cases of cerebral vein thrombosis were observed.

It is quite surprising that, despite relevant alterations in coagulation parameters of COVID patients, no cases of cerebral vein thrombosis have been reported till now. An underestimation cannot be excluded.

Our case suggests that in COVID patients with high Ddimer and fibrinogen levels that complain headache, seizure or focal deficits, a venous angio-CT should be performed in order to exclude cerebral vein thrombosis.

\section{Compliance with ethical standards}

Conflict of interest The authors declare that they have no conflict of interest.

Ethical approval None.

\section{References}

1. CheN ZM, Dong X, Qu J, Gong F, Han Y, Qiu Y, Wang J, Liu Y, Wei Y, Xia J, Yu T, Zhang X, Zhang L (2020) Epidemiological and clinical characteristics of 99 cases of 2019 novel coronavirus pneumonia in Wuhan, China: a descriptive study. Lancet 395:507-513

2. Tang N, Li D, Wang X, Sun Z (2020) Abnormal coagulation parameters are associated with poor prognosis in patients with novel coronavirus pneumonia. J Thromb Haemost 18:844-847

3. Han H, Yang L, Liu R, Liu F, Wu KL, Li J, Liu XH, Zhu CL (2020) Prominent changes in blood coagulation of patients with SARSCoV-2 infection. Clin Chem Lab Med 58:1116-1120. https://doi. org/10.1515/cclm-2020-0188

4. Kollias A, Kyriakoulis KG, Dimakakos E, Poulakou G, Stergiou GS, Syrigos K (2020) Thromboembolic risk and anticoagulant therapy in COVID-19 patients: emerging evidence and call for action. Br J Haematol 18:846-847. https://doi.org/10.1111/bjh.16727

5. Mao L, Jin H, Wang M, Hu Y, Chen S, He Q, Chang J, Hong C, Zhou Y et al (2020) Neurologic manifestations of hospitalized patients with coronavirus disease 2019 in Wuhan, China. JAMA Neurol 10. https://doi.org/10.1001/jamaneurol.2020.1127

Publisher's note Springer Nature remains neutral with regard to jurisdictional claims in published maps and institutional affiliations. 